\title{
Unlinked anonymous testing to estimate HIV prevalence among pregnant women in Catalonia, Spain, 1994 to 2009
}

D Carnicer-Pont (dcarnicer@iconologia.net) ${ }^{1,2,3}$, J Almeda ${ }^{4,3}$, J Luis Marin 5 , C Martinez ${ }^{5}$, M V Gonzalez-Soler ${ }^{1,3}$, A Montoliu ${ }^{1,3}$,

R Muñoz ${ }^{1}$, J Casabona ${ }^{1,2,3}$, the HIV NADO working group ${ }^{6}$

1. Centre of Epidemiological Studies of HIV/AIDS and STI of Catalonia (CEEISCAT), Badalona, Spain

2. Department of Paediatrics, Obstetrics and Gynaecology of the Autonomous University of Barcelona.(UAB), Bellaterra, Spain

3. CIBER, Epidemiology and Public Health (CIBERESP), Madrid, Spain

4. Primary Health Department Costa de Ponent, Catalan Health Institute (ICS), IDIAP-Jordi Gol, L'Hospitalet del Llobregat, Spain

5. The Catalan Neonatal Early Detection Programme, Service of Biochemistry and Molecular Genetics, Hospital Clinic, Faculty of Medicine, Barcelona, Spain

6 . The members of the group are listed at the end of the article

Citation style for this article:

Carnicer-Pont D, Almeda J, Luis Marin J, Martinez C, Gonzalez-Soler MV, Montoliu A, Muñoz R, Casabona J, the HIV NADO working group. Unlinked anonymous testing to estimate HIV prevalence among pregnant women in Catalonia, Spain, 1994 to 2009.

Euro Surveill. 2011;16(32):pii=19940. Available online: http://www.eurosurveillance.org/ViewArticle.aspx?Articleld=19940

Article published on 11 August 2011

This paper estimates the prevalence of human immunodeficiency virus (HIV) infections in women giving birth and women voluntarily terminating pregnancy over a period of sixteen years in Catalonia. Samples for HIV antibody detection were collected from the Neonatal Early Detection Programme for congenital metabolic diseases that covers $99 \%$ of infants born in Catalonia. The sampling method collected information of $50 \%$ of births every year and of all women attending three clinics for voluntary interruption of pregnancy. Using two sequential immunoassays we analysed unlinked anonymous blood spot samples from 549,689 newborns between 1994 and 2009 and from 31,904 women who voluntarily interrupted pregnancy between 1999 and 2006. HIV prevalence among women giving birth decreased from 3.2 per 1,000 in 1994 to 1.7 per 1,000 in 2009 ( $p<0.01)$ and the mean age of infected mothers increased from 26 years in 1994 to 32 years in $2009(p=0.001)$. A decrease in HIV prevalence was also observed in women voluntarily terminating pregnancy, from 2.3 per 1,000 in 1999 to 1.0 per 1,000 in 2006 ( $p<0.01)$. In contrast, estimated HIV prevalence in mothers born outside Spain increased from 2.2 per 1,000 in 2002 to 3 per 1,000 in 2009 ( $p<0.01$ ) and their average age increased from 27 years in 2003 to 31 years in 2009 ( $p<0.01)$.

\section{Introduction}

Accurate estimates of the number of individuals living with human immunodeficiency virus (HIV) infection are essential for the planning and monitoring of HIV prevention and care programmes. Studies of HIV prevalence in sentinel populations are one of the key strategies to monitor the epidemic [1], and one of the methods that has been widely used in sentinel populations is unlinked anonymous testing (UAT) [2]. By 1987, the United States and the United Kingdom (UK) had already put in place UAT programmes to improve the understanding of the evolving epidemic in their countries. Over the years, UAT in pregnant women has been substituted by regular antenatal screening programmes in most European and North American countries and only few countries such as the UK and Spain still maintain this surveillance approach.

The UAT to monitor trends of HIV infection in women giving birth in Catalonia is performed annually on blood samples collected from newborns. The presence of HIV antibodies in the newborn reflects maternal infection due to the passive transfer of maternal antibodies to the infant. Since this testing is unlinked (prior to HIV testing the link between the specimen and the personal identifying information is removed) and anonymous (the health staff cannot identify an individual's test result), it is impossible to inform the women of the test results.

The use of sentinel populations to estimate prevalence is a common practice and UAT in these populations has been seen since the beginning of its use as a good tool to prevent participation bias associated with populations at risk (the higher the risk the lower the will to participate) [2] Catalonia UAT has proven to be an easy and cost-effective tool to monitor prevalence because of its association with other screening programmes that provide very good coverage of the population of women of childbearing age. The objective of this study was to describe the HIV epidemic and trends in women giving birth and those terminating pregnancy as an estimation of the HIV prevalence in pregnant women in Catalonia.

\section{Methods}

In the period from 1994 to 2009, we used samples from newborns of women living in Catalonia collected as part of an annual cross-sectional study. In addition, we analysed blood samples from women voluntarily terminating their pregnancy in three selected clinics in Catalonia in the period from 1999 to 2006. 
Women giving birth

The Catalan Neonatal Early Detection Programme (NEDP) has been collecting blood spot samples from all newborns since 1994. These samples are used to determine hypothyroidism, phenylketonuria and cystic fibrosis in newborns. This screening is carried out annually by the Institute of Clinical Biochemistry (Institut de Bioquímica Clínica, IBC) and covers 99\% of all infants born in Catalonia [3].

For 1994, we obtained samples for HIV antibody detection from this pool of the NEDP for the period between August and December. For all subsequent years until the end of 2009, we selected samples from every second month. The total sample obtained represents half of the yearly newborns in Catalonia [4].

Before determination of HIV antibody status, the samples from women giving birth were screened for neonatal metabolic disease. The remaining dried blood spots were used for the HIV antibody detection. This is an UAT programme to estimate HIV prevalence in pregnant women. Although this meant that the women could not be informed of the result, all of them were offered HIV testing as part of their routine screening during pregnancy, and women testing positive there were offered treatment. The annual number of samples needed to estimate a prevalence of between 1.8 and $2.8 \%$ with a $95 \%$ confidence interval and a precision of $0.06 \%$ is around 35,000 samples. The yearly mean of samples obtained during our period of study was 34,391 [5].

\section{Women terminating pregnancy}

The second source of information to monitor HIV prevalence in pregnant women were blood samples taken from women attending three specialised medical centres to terminate their pregnancies. Informed consent was required to obtain these samples. All dried blood spots from women terminating pregnancy were sent to the IBC for HIV antibody detection.

There were at least 11,000 voluntary interruptions of pregnancy annually in the three centres participating in the study. Testing all samples from these centres, we can therefore estimate a prevalence of 2 per 1,000 with a $95 \%$ confidence interval and a precision of $0.08 \%$.

In women terminating their pregnancy, information on age was available for those sampled in the years 1999 to 2006. Mean age comparisons between women giving birth and those terminating pregnancy have been performed for this period of time. Information about country of origin was poor and discarded in the analysis of this set of samples.

\section{Sample analysis}

Sample collection and HIV antibody detection was done using dried blood spots. Two drops of blood were collected on filter paper discs (Schleicher and Schuell no. 903TM, Dassel, Germany) and stored at 4 ${ }^{\circ} \mathrm{C}$ until used. HIV antibodies were determined using a modified Serodia IgG antibody-capture particle agglutination test (GACPAT) for HIV-1 (Fujirebio Diagnostics) [6]. Positive samples were sent to the Microbiological Service of the University Hospital Germans Trias I Pujol (HUGTiP) to confirm the results using an IgG antibody capture ELISA for HIV-1 and HIV-2. Until 2001 this was done using the GACELISA test (Murex, UK) [7]. In 2002 this confirmatory test was replaced with the Pasteur HIV-1/2 GenElavia Mixt ELISA (BioRad, Spain) after checking that normal and external valid values were similar for both tests [8].

Variables collected in the study were HIV status of the pregnant women, age and country or region of origin. Confidentiality for both data sets (women giving birth and those terminating pregnancy) was ensured by using a computer-aided coding process at the NEDP. The results of HIV antibody testing could not be correlated with any patient identification number.

The annual HIV prevalence among women of childbearing age was computed as the number of HIVpositive samples divided by the total number of HIV-positive and HIV-negative samples tested each year, with $95 \%$ confidence intervals. Trends were analysed using the Cochran-Armitage test. Data were analysed using Stata SE 8. For the age variable, a comparison between women giving birth and those terminating pregnancy was done by non-parametric Mann-Whitney U-test.

\section{Results}

Among the 581,593 blood spot samples analysed, 549,689 were from infants born during the years 1994 to 2009 and 31,904 from women terminating their pregnancy during the years 1999 to 2006 . We obtained 1,081 HIV positive results, representing a global prevalence of 1.85 per 1,000. Overall, we tested $54 \%$ of all women giving birth in Catalonia, ranging from $53 \%$ in

\section{FIGURE 1}

HIV prevalence in women giving birth, Catalonia, $1994-2009(n=549,689)$

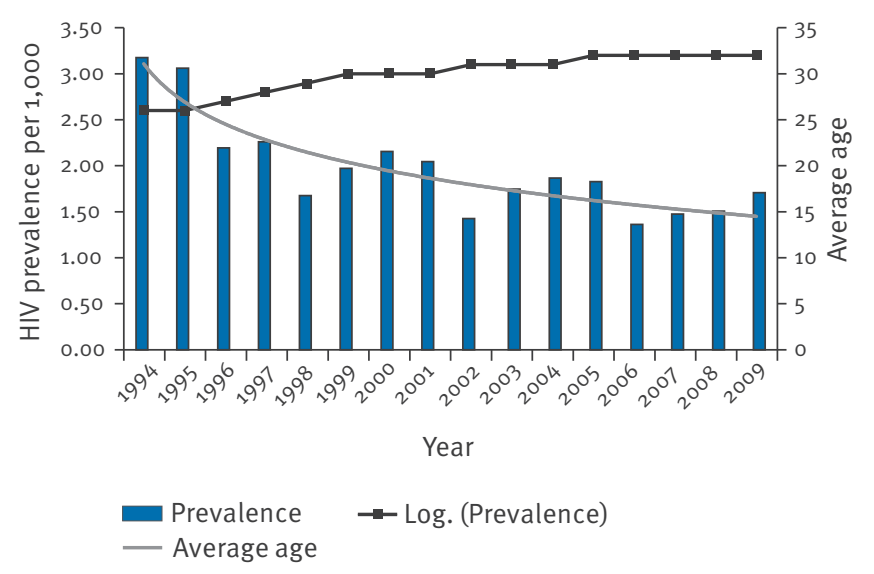

HIV: human immunodeficiency virus. 
1996 to $46 \%$ in 2008 , and $24 \%$ of those terminating pregnancy from 1999 to 2006.

Our estimates show a decreasing trend in HIV prevalence from 1994 (3.2 per 1,000) to 2002 (1.4 per 1,000; p<0.01). It then remains steady until 2009 (1.7 per 1,000; $p=0.145$ ) (Figure 1).

Information on age was available in 562,977 of 581,593 samples (97\%). The mean age for all women was 30.3 years, similar in HIV-seropositive (30.8 years) and HIVseronegative women (30.3 years). However, the mean age of HIV-infected mothers was lower among those born outside Spain (29 years) than among Spanish mothers (33 years) ( $p<0.001$ ), reflecting the mean age of the general population: mean age of foreign and Spanish mothers, 29 years and 32 years, respectively.

When analysing the data by age, we saw a decreasing logarithm trend in the age group of 20 to 29 year-olds ( $p<0.001$ ) and no significant trend in the age groups under 20 years $(p=0.41)$, from 30 to 39 years $(p=0.04)$ and 40 years and older $(p=0.01)$ (Figure 2$)$.
HIV prevalence in women giving birth by country or region of origin

Country of birth information was available only for women giving birth between 2002 and 2009, with poor completion in 2002 (country of origin was unknown in $79 \%$ of records) but much better completion in 2009 (missing information in only $2 \%$ of the records).

We observed an increasing trend in HIV prevalence between 2007 (1.6 per 1,000) and 2009 (3 per 1,000) among women born abroad, compared to lower prevalence rates and a decreasing trend from 1.3 per 1,000 to 1.1 per 1,000 among Spanish women in the same period. Prevalence was particularly high among those from Sub-Saharan Africa, reaching 6.9 per 1,000 in 2004 and 5.4 per 1,000 in 2009 (Figure 3).

HIV prevalence trends in women terminating pregnancy versus those giving birth Information on women terminating pregnancy was available only for the period 1999 to 2006. We analysed samples from 31,904 women who interrupted their pregnancy in the three participating centres, representing $27 \%$ of all women who legally interrupted pregnancy in Catalonia.

\section{FIGURE 4}

HIV prevalence in women terminating pregnancy versus those giving birth, Catalonia, 1999-2006 ( $\mathrm{n}=325,223)$

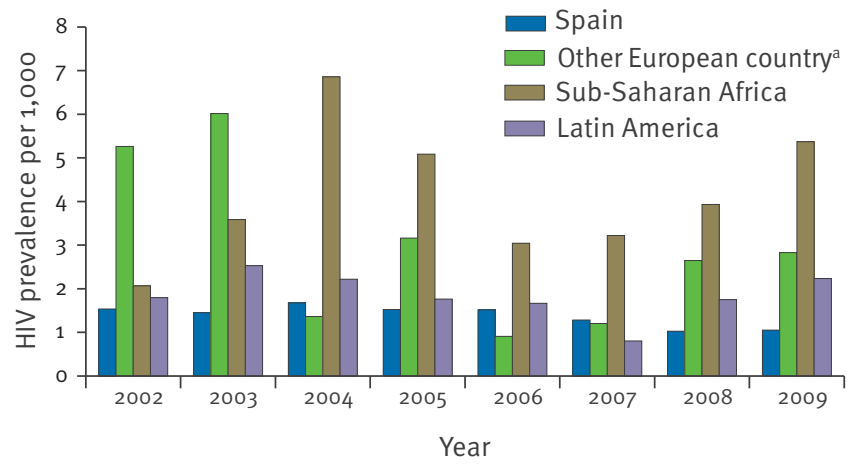

HIV: human immunodeficiency virus.

${ }^{a}$ European Union plus European Free Trade Association countries.

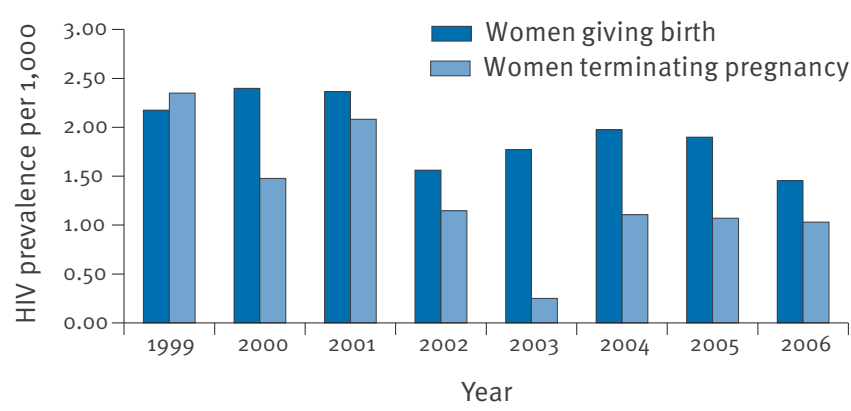

HIV: human immunodeficiency virus.

\section{FIGURE 2}

HIV prevalence in women giving birth, by age, Catalonia, 1994-2009 ( $\mathrm{n}=549,689)$

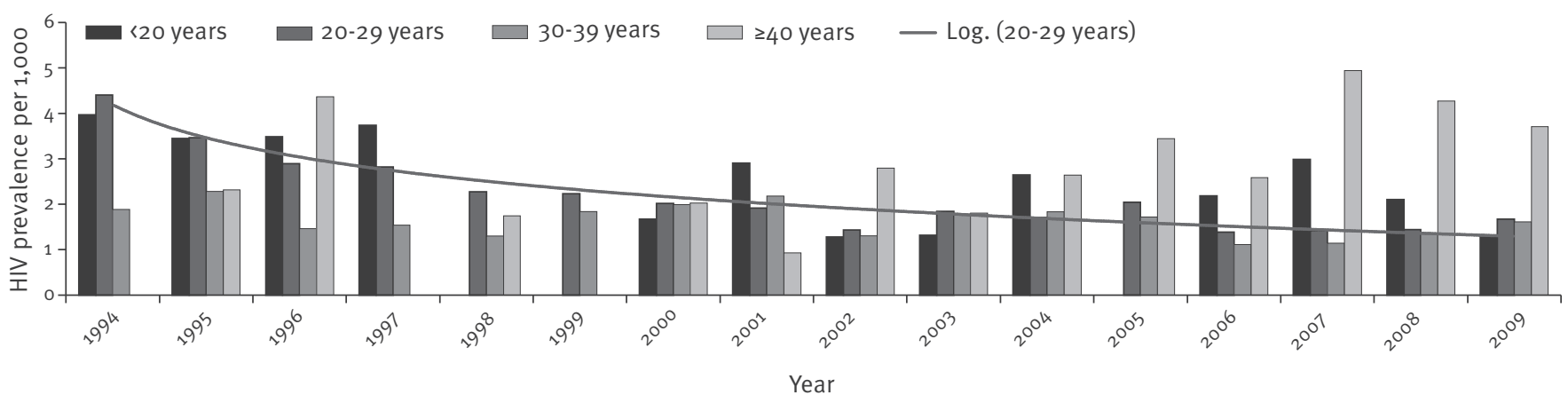

HIV: human immunodeficiency virus. 
HIV prevalence during this time period did not differ between women terminating pregnancy and women giving birth $(p=0.06)$, with 42 of $31,904(13 \%)$ and 522 of 293,120 (18\%) HIV-positive.samples, respectively. HIV-positive women terminating pregnancy were younger than those giving birth (average age 26.6 versus 30.6 years; p 0.0001 ) for the same time period. A non-significant decreasing trend in HIV prevalence was observed in women who voluntarily interrupted pregnancy $(p=0.066)$ from 2.3 per 1,000 in 1999 to 1.0 per 1,000 in 2006 (Figure 4 ).

\section{Discussion and conclusion}

Unlinked anonymous surveillance of newborns and women interrupting pregnancy allowed us to estimate the HIV prevalence among pregnant women as a surrogate for HIV infection prevalence in women of childbearing age. We found this method to be feasible and reliable in Catalonia. Our study provides 16 years of meaningful information, if limited by covering only the variables age and country of origin.

Data from women voluntarily interrupting pregnancy were included with the objective of identifying any potential bias due to voluntary interruption of pregnancy among women with higher rates of HIV infection [9]. However, their HIV prevalence was similar to the one found in women giving birth. Nevertheless, the small sample studied cannot guarantee the representativeness for all interrupted pregnancies performed in
Catalonia, because important hospitals did not contribute data.

The HIV prevalence rates followed a decreasing trend between 1994 and 2002, rose in the following three years (2003 to 2005), dropped in 2006 and then increased again in the years up to 2009. This rise was observed not only in Sub-Saharan African mothers but also in other European countries and Latin America. As expected, the seroprevalence observed in this study reflected the prevalence in the regions where the study population originated. For the decade 2000 to 2010 , the HIV prevalence in Sub-Saharan Africa is reported as around 50 per 1,000, in Latin America around 5 per 1,000 for the same time period and in other European countries of around 2 per $1,000[10,11]$.

Compared to other autonomous regions of Spain for which data are available, Catalonia has since the early 905 had one of the highest HIV prevalence rates $[12,13]$, after the Canary and Balearic Islands. Over the period from 1995 to 1998 prevalence rates we observed in Catalonia decreased from 3.1 to 1.7 per 1,000. Other European countries such as Germany, Italy and the UK, where UAT has been used since the early 1990s, had different experiences in the same time period. In Italy $[14,15]$ rates did not change significantly as well as in Scotland [15] and Germany [15].* Information available from the years 1999 to 2004, shows that HIV prevalence estimations from UAT in Catalonia followed a

TABLE**

HIV prevalence rates per 1,000 samples tested from unlinked anonymous testing in some European countries

\begin{tabular}{|c|c|c|c|c|c|c|}
\hline Year & Catalonia (Spain) & Spain & Germany & Italy & Scotland (UK) & UK (all) \\
\hline 1995 & $3^{\mathrm{a}}$ & $1^{\mathrm{a}}$ & NA & $0.9^{b}$ & NA & NA \\
\hline 1996 & $2.2^{\mathrm{a}}$ & $1^{\mathrm{a}}$ & NA & $0.7^{b}$ & $\mathrm{NI}$ & NA \\
\hline 1997 & $2.2^{\mathrm{a}}$ & $1.3^{\mathrm{a}}$ & NA & $0.6^{\mathrm{b}}$ & $\mathrm{NI}$ & NA \\
\hline 1998 & $1.7^{\mathrm{a}}$ & $1.4^{\mathrm{a}}$ & NA & $0.8^{b}$ & $\mathrm{NI}$ & NA \\
\hline $1999^{c}$ & 2 & 1.6 & 0.2 & 0.8 & 0.2 & 0.7 \\
\hline $2000^{c}$ & 2.2 & 1.3 & 0.2 & - & 0.5 & 0.9 \\
\hline $2001^{\mathrm{c}}$ & 2 & 1.4 & 0.3 & 0.8 & 0.3 & 1.1 \\
\hline $2002^{c}$ & 1.4 & 1.6 & 0.2 & 0.7 & 0.6 & 1.5 \\
\hline $2003^{c}$ & 1.7 & 1.6 & NA & NA & 0.3 & 1.7 \\
\hline $2004^{c}$ & 1.9 & 1.5 & NA & NA & 0.5 & 1.9 \\
\hline 2005 & $1.8^{\mathrm{d}}$ & $1.3^{\mathrm{d}}$ & NA & NA & NA & NA \\
\hline 2006 & $1.5^{\mathrm{d}}$ & $1.7^{\mathrm{d}}$ & NA & NA & NA & NA \\
\hline 2007 & $1.5^{\mathrm{d}}$ & $1.3^{\mathrm{d}}$ & NA & NA & NA & NA \\
\hline 2008 & $1.5^{\mathrm{d}}$ & $1.5^{\mathrm{d}}$ & NA & NA & $N A$ & NA \\
\hline 2009 & $1.7^{\mathrm{e}}$ & NA & NA & NA & NA & NA \\
\hline
\end{tabular}

NA: not available; NI: not included.

a Source: [12].

b Source: [14].

' Source: [15].

d Source: [13].

e Source: original date from the Unlinked Anonymous Testing Programme in Catalonia. 
different trend than, for example, those in the UK [15] where the prevalence was systematically increasing over the years (Table).

HIV prevalence among pregnant women in the World Health Organization European Region [16] has been monitored using three methods: seroprevalence studies based on UAT of either newborns or pregnant women, seroprevalence studies based on multiple data sources (for other sexually transmitted diseases such as syphilis or hepatitis), and systematic collection and reporting of the results of diagnostic testing carried out among pregnant women in antenatal care or at delivery. Most of these countries are nowadays prioritising the third method because of increased accessibility to testing through antenatal care and the establishment of national registers of pregnant women, thus making UAT potentially redundant.

In Catalonia, UAT of neonatal dried blood spots taken for metabolic screening has been carried out since 1994 and the policy of universal antenatal HIV screening was introduced in 1996 [17]. However, to obtain prevalence rates through antenatal HIV screening, we would need information on the number of pregnant women tested for HIV, and in our country the systems to obtain this information are not yet in place. Therefore, UAT has been continued, mainly because data and sample collection are simple, cheap and have the added advantage of providing unbiased prevalence rates. On the other hand, UAT of blood taken from women voluntarily interrupting their pregnancy was stopped in 2007 due to small samples and low representativeness.

As in other regions of Spain, pregnant women in Catalonia are offered HIV screening in the first trimester of pregnancy and, if they are at risk of exposure, also during the third trimester of pregnancy [18]. A survey of HIV testing coverage conducted in Catalonia in the year 2000 found that $89 \%$ of women were tested during pregnancy, which at the time was assessed as good coverage $[19,20]$. Current policy aims at $100 \%$ coverage, and there is concern regarding subpopulations that never reach antenatal care because of low educational level, low interest or arrival to the country at the time of delivery. It is worth noting that between the years 2000 and 2009, the foreign population in Catalonia has increased from $2.9 \%$ to $15.9 \%$ of the total population [21]. Targeted efforts to include foreign mothers are not in place or of dubious efficacy. Strengthening surveillance and promoting testing at voluntary counselling and testing sites may support the already existing and well functioning antenatal care programme. Another important use of the UAT data is to produce estimates of HIV infections in order to plan and monitor the HIV prevention and care programs.

In conclusion, since routine HIV surveillance does not provide data on undiagnosed infections and there is evidence that immigrants may not have access to prenatal care until delivery, data from UAT in Catalonia is still useful to complement the epidemiological data on this infection. Moreover, UAT among pregnant women is still the best available surrogate for HIV prevalence among the sexually active female population.

The members of the HIV NADO working group are:

CEEISCAT, Hospital Universitari Germans Trias i Pujol, Badalona (J Masip, A Esteve, JA Rodrigo-Pendàs); Servei de Microbiologia, Hospital Universitari Germans Trias i Pujol, Badalona (V Ausina, L Matas, E Martró, D Sánchez); Unitat de Cribratge Perinatal. LCE. CDB. Corporació Sanitària Clínic, Barcelona (A Maya, M Puliol, F Borja, J M Santos); Direcció General de Salut Pública, Departament de Salut (J L Taberner, R Prats); Servei d'Informa_ció i Estudis, Direcció General de Recursos Sanitaris, Departament de Salut (R Gispert, J J Coll, A Calancha, R Bosser); Clinica d'Ara-Tutor Médica (S Barambio, J Fernández, Y Trejo); Clínica E.M.E.C.E. (M Sánchez); Centro Casanova de Ginecología y Planificación, SA (R Novo, M Palma).

\section{Authors' correction}

At the request of the authors, the following changes were made on 18 August 2011:

*The sentence that read 'In Italy rates did not change significantly as well as in Scotland [14], in Germany (Berlin) and the UK (London inner city), there was an increasing trend from 0.4 to 0.7 and 1.8 to 2.2 , respectively [14].' was replaced by the following: 'In Italy $[14,15]$ rates did not change significantly as well as in Scotland [15] and Germany [15].'

** Numbers and sources in the table were corrected.

$\star * *$ References were corrected and renumbered in the text and reference list.

\section{References $^{* * *}$}

1. Global Programme on AIDS and Programme of STD World Health Organization. J Acquir Immune Defic Syndr. 1989;2(3):248-55.

2. Gill ON, Adler MW, Day NE. Monitoring the prevalence of HIV. BMJ. 1989;299(6711):1295-8.

3. Parry JV, Mortimer PP. An immunoglobulin G antibody capture particle-adherence test (GACPAT) for antibody to HIV-1 and HTLV-I that allows economical large-scale screening. AIDS.1989;3(3):173-6.

4. Parry JV, Perry KR, Mortimer PP. Sensitive assays for viral antibodies in saliva: an alternative to tests on serum. Lancet. 1987;2(8550):72-5.

5. Meda N, Gautier-Charpentier L, Soudre RB, Dahourou H, Ouedraogo-Traore R, Ouangre A, et al. Serological diagnosis of human immuno-deficiency virus in Burkina-Faso: reliable, practical strategies using less expensive commercial test kits. Bull World Health Organ. 1999;77(9):731-9.

6. Cribratge neonatal d'hipotiroïdisme, fenilcetonuria i fibrosi quística. En: Indicadors de salut maternoinfantil a Catalunya (1997-1999). [Neonatal screening of hypothyroidism, phenylketonuria and cystic fibrosis. In: Mother and child health indicators in Catalonia (1997-1999)]. Barcelona: Generalitat de Catalunya, Department of Health". [Accessed 12 Aug 2009). Spanish. Available from: http://www.gencat.cat/ salut/depsalut/html/ca/dir1951/acnp391.htm

7. Anuari estadistic de Catalunya 2005. [Annual statistical report of Catalonia 2005]. Barcelona: Generalitat de Catalunya, Catalan Institut of Statistics; 2005 . Spanish. Available from: http://www.idescat.cat/pub/?id=aec

8. Lwanga S, Lemeshow S. Sample size determination in health studies.Genève: World Health Organization, 1991. 
9. Abeni DD, Porta D, Perucci CA. Deliveries, abortion and HIV-1 infection in Rome, 1989-1994. The Lazio AIDS Collaborative Group. Eur J Epidemiol. 1997;13(4):373-8.

10. UNAIDS: Global report. UNAIDS report on the global AIDS epidemic 2010. UNAIDS; 2010. Available from: http://www. unaids.org/en/media/unaids/contentassets/documents/ document/2010/20101130_GR2010_annex1_table_en.xls

11. Asamoah-Odei E, Garcia Calleja JM, Ties Boerma J. HIV prevalence and trends in Sub-Saharan Africa: no decline and large subregional differences. Lancet. 2004;364(9428):35-40.

12. Estudio anónimo y no relacionado sobre la prevalencia de anticuerpos anti-VIH 1 y 2 en recién nacidos vivos de 8 comunidades autónomas. Años 1996-2005. [Unlinked anonymous study about HIV 1 and 2 antibodies in new born of 8 autonomous communities. Years 1996-2005]. Madrid: Ministerio de Ciencia e Innovacion [Ministry of Science and Innovation]; Aug 2010. Spanish. Available from: http://www. isciii.es/htdocs/pdf/anr_nacidos.pdf

13. Estudio anónimo y no relacionado sobre la prevalencia de anticuerpos anti-VIH en recién nacidos vivos de 6 comunidades autónomas. Años 2003-2008. [Unlinked anonymous study about HIV 1 and 2 antibodies in new born of 6 autonomous communities. Years 2003-2008]. Madrid: Ministerio de Ciencia e Innovacion [Ministry of Science and Innovation]; Aug 2010. Spanish. Available from: http://www.isciii.es/htdocs/pdf/ anr nacidos.pdf

14. Girardi E, Vanacore P, Costa F, Solmone M, Angeletti C, Capobianchi MR, et al,Trends in HIV prevalence among pregnant women in Italty, 1994 to 2002. J Acquir Immune Defic Syndr. 2006;41(3):361-4.

15. European Centre for Epidemiological Monitoring of AIDS. HIV/ AIDS surveillance in Europe. End-year report 2001. SaintMaurice: Institut de Vielle Sanitaire; 2002, no. 66. Available from: http://www.ecdc.europa.eu/en/activities/surveillance/ hiv/Documents/report_eurohiv_endyear_2001.pdf

16. EuroHIV. HIV/AIDS surveillance in Europe. Mid-year report 2005. Saint-Maurice: Institut de Vielle Sanitaire; 2006. Available from: http://www.invs.sante.fr/publications/2006/ eurohiv_rapport72/eurohiv_rapport72.pdf

17. Cortina-Borja M, Cliffe S, Tookey P, Williams D, Cubitt WD, Peckham C. HIV prevalence in pregnant women in an ethnically diverse population in the UK: 1998-2002. AIDS 2004;18(3):535-40.

18. EuroHIV. Report on the EuroHIV 2006 survey on HIV and AIDS surveillance in the WHO European Region. Saint-Maurice: Institut de Vielle Sanitaire; 2007. Available from: http://www. invs.sante.fr/publications/2007/eurohiv_2006/HIV_AIDS_Web. pdf

19. Pla de Salut de Catalunya, 1996-1998. [Health Plan of Catalonia, 1996-1998]. Barcelona : Departament de Sanitat i Seguretat Social [Department of Health and Social Security]; 1997. Spanish. Available from: http://www.saveva.com/ domamPlus/pub/depsalut/pdf/325_329_96.pdf

20. Protocol de seguiment de l'embaràs a Catalunya. [Protocol for the follow up of pregnancy in Catalonia]. Barcelona: Departament de Sanitat i Seguretat Social [Department of Health and Social Security]; 1998. 109 p. Spanish. Available from: http://www.gencat.cat/salut/depsalut/pdf/ protsegui2006.pdf

21. Panel de expertos de GeSIDA y Plan Nacional sobre el Sida. [Expert Panel of the study group on AIDS and National Plan for AIDS]. Recomendaciones de GeSIDA/Plan Nacional sobre el Sida respecto al tratamiento antirretroviral en adultos infectados por el virus de la inmunodeficiencia humana. [Recommendations of GeSIDA/National Plan for AIDS on antiretroviral therapy in adults infected with human immunodeficiency virus]. Madrid: GeSIDA-SEIMC; Jan 2007. Spanish. Available from: http://www.gesida.seimc.org/ pcientifica/fuentes/DcyRc/DcyRc_Recomendaciones_TAR GESIDA-PNS_Impver1.pdf

22. Perez K, Blanch C, Casabona J, Almeda J, Coll O, COBEMB. Coverage of HIV testing among pregnant women in Catalonia. Spain. Eur J Public Health. 2004:14(3);261-6.

23. Evolució de la població total i estrangera. 2000-2010. [Evolution of the total population in foreigners 2000 2010]. Barcelona: Institut d'estadística de Catalunya [Institut of Statistics of Catalonia]. [Accessed 15 Jan 2011]. Spanish. Available from: http://www.idescat.cat/ poblacioestrangera $/ ? b=0$ 